\title{
The causative drugs and the prevalence of severe bullous hypersensitivity reactions
}

\author{
Ekaterina Vertieva ${ }^{1 *}$, Pavel Kolkhir ${ }^{2}$, Natalia Teplyuk ${ }^{3}$ \\ From 6th Drug Hypersensitivity Meeting (DHM 6) \\ Bern, Switzerland. 9-12 April 2014
}

\begin{abstract}
Background
According to recent studies about 1-3\% of hypersensitivity reactions are accompanied by skin eruptions. Among these toxic epidermal necrolysis (TEN) and StevensJohnson syndrome (SJS) are rare and the most severe adverse cutaneous drug reactions that predominantly involve the skin and mucous membranes. TEN and SJS affecting approximately 1-4/1,000,000 annually with average reported mortality rate $25-35 \%$ (TEN), and $1-5 \%$ (SJS). The aim of this work was to study the frequency of severe bullous delayed allergic reactions, like TEN and SJS, their clinical presentations, causative drugs, treatment and the diagnostic approach required.
\end{abstract}

\section{Method}

We followed up 33 patients ( 7 males, 26 females) aged 21-80 years with various severe bullous dermatoses in dermatology department of our hospital.

\section{Results}

Most of the patients had drug hypersensitivity reactions $(n=22)$ and most of them were female older than 70 years. 3 of them had TEN and 7 suffered from SJS. The causative drugs of TEN and SJS were sulfonamides $(23 \%, \mathrm{n}=5)$, NSAIDs $(14 \%, \mathrm{n}=3)$ and anticonvulsants (9\%, $\mathrm{n}=2$ ). The most common drug was sulfamethoxazole $(18 \%)$. The most severe reactions were caused by sulfamethoxazole (13\%), metamizole (4\%) and carbamazepine (9\%). Mortality rate was about $4 \%(n=1)$.

\section{Conclusion}

The results of our study indicate that TEN and SJS may occur in about $32 \%$ patients with severe bullous dermatoses. Sulfanonamides, NSAIDs and anticonvulsants are the most frequently implicated drugs. Diagnosis relies

${ }^{1}$ I.M. Sechenov First Moscow State Medical University, Russia

Full list of author information is available at the end of the article mainly on clinical symptoms together with the results of a skin biopsy. Due to the high risk of mortality, management of patients with severe bullous dermatoses, especially TEN and SJS, requires rapid identification and interruption of the culprit drug, specialized supportive care and immunomodulatory therapy.

\section{Authors' details}

${ }^{1}$ I.M. Sechenov First Moscow State Medical University, Russia. ${ }^{2}$ I.M. Sechenov First Moscow State Medical University, Allergy Department, Russia. ${ }^{3}$ I.M. Sechenov First Moscow State Medical University, Dermatology Department, Russia.

Published: 18 July 2014

\section{doi:10.1186/2045-7022-4-S3-P16}

Cite this article as: Vertieva et al:: The causative drugs and the prevalence of severe bullous hypersensitivity reactions. Clinical and Translational Allergy 2014 4(Suppl 3):P16.
Submit your next manuscript to BioMed Central and take full advantage of:

- Convenient online submission

- Thorough peer review

- No space constraints or color figure charges

- Immediate publication on acceptance

- Inclusion in PubMed, CAS, Scopus and Google Scholar

- Research which is freely available for redistribution
() Biomed Central 